\title{
Reliability and Construct Validity:
}

\author{
Of the Basketball Movement Skills Instrument
}

\author{
Silvy Juditya*, Adang Suherman, Amung Ma'mun, Agus Rusdiana \\ Sports Education Study Program, School of Postgraduate Studies \\ Universitas Pendidikan Indonesia \\ Bandung, Indonesia \\ *juditya@student.upi.edu, adangsuherman@upi.edu, amung@upi.edu,agus.rusdiana@upi.edu
}

\begin{abstract}
This study was aimed at testing the construct validity of the basketball basic motion skills test instrument (ITK GDBB). The research used descriptive method of 3 basketball experts in the city of Cimahi; 3 experts are the expert in basketball. The instrument used was the ITB GDBB developed by Silvy (2019) consisting of top passing, bottom passing, top service, bottom service, chest passing, bounding passing, overhead passing, and leading ball (dribbling). This instrument consists of 76 items that cover 4 domains in basketball, namely chest pass, overhead pass, bound pass, and dribbling. The validity method used the construct validity of different power types. For the reliability method, it used the Kuder Ricardson (KR) and Objectivity analysis. The results of the construct validity analysis of a total of 76 items show that the score is ranged from 0.67 to 1.00 . The construct validity value of 71 items in the basketball game is in the high category $(=1.00), 5$ items are in the sufficient category, the relativity score is ranged from 0.75 to 0.98 , and the objectivity score is ranged from 0.89 to 0.95 . The conclusion is that this test instrument can be used as a standardized basic motion skill test for standardized large ball games for validity in basic motion skills in basketball games for grade VII junior high school students.
\end{abstract}

Keywords: basic motion skills, basketball, instruments, reliability, validity

\section{INTRODUCTION}

Physical education is one of the subjects studied by students, where in the process of learning physical education in schools a lot of motion learning material delivered by a teacher to students, it is quite clearly illustrated in the basic competencies found in the standard content for PJOK learning. Learning Physical education that is learned by students basically focuses on learning the skills of motion, games and about techniques in sports. Basketball game is one of the learning materials that enter into one of the basic competencies of the big ball game contained in the curriculum of physical education, sports and health at the school level both at the elementary school, junior and senior high school and even at the vocational high school. Achievement of the big ball learning process at school that students are able to practice the basic motion of each big ball game delivered by the teacher and to know the extent to which students are able to do basic motion mastery at each big ball game requires an assessment or evaluation process to measure the success of a process learning, but success in the learning evaluation or evaluation process depends on the quality and appropriateness of the tools or instruments used to measure with what they want to be measured. The evaluation process is a major requirement that must be present in the learning process although the conditions that often occur is a process of curriculum change, but the evaluation process cannot be eliminated. As expressed by [1] No matter how frequently the evaluation system changes, the presence of evaluation in the world of education and teaching cannot be eliminated. Evaluation is needed to monitor the extent of the success of learning activities in their efforts to achieve educational goals. There are three main reasons why in educational activities always require evaluation. First, when viewed from a process approach, there is a relationship between educational goals, learning processes and evaluation. Second, evaluating the learning outcomes is one of the characteristics of professional educators. Third, when viewed from an institutional approach, educational activities are management activities, which include planning, programming, organizing, organizing, acting, controlling, and evaluating. The importance of the role of evaluation in the learning process requires attention to the quality of an instrument or measuring instrument used to assess the mastery of basic motion in big ball games. The quality of a basic motion skills test is largely determined by the quality of each item in the assessment instrument used. The quality of a measuring instrument is determined by how much the quality of the test items on the instrument is not on how many test items there are on an instrument. In other words, a basic motion skills test instrument that contains several high quality test items although in small amounts will be far more useful than a basic motion skills test instrument that contains dozens of test items but has a low quality. Low-quality test items not only reduce the function of the test, but also will provide measurement results that are not in accordance with what will be measured.

Talking about a research that raises a problem regarding an instrument for evaluating learning outcomes such as research conducted by Khaerudin [1], Mutaqin [2], Kereh [3], Stanton [4], Markovic [5], Vuleta [6], and Pojskić [7] both spoke of the importance of an instrument to be used that must have validity and reliability, but from some of these studies there is no basic motion skill instrument in basketball that has an adjusted level of validity and reliability with learning materials at junior high school level and is devoted to junior high school students, especially junior high school students class VII. The purpose of 
skills in the form of the initial attitude, the attitude of the executing and the final attitude in the basketball game starting from the chest pass, overhead pass and bound pass. As for the steps taken in the process of testing the validity of the basketball basic motion skills test instrument namely construct validity with different power analysis then reliability testing with Kuder Ricardson (KR) analysis and objectivity type reliability.

\section{RESULTS}

Data obtained from the results of the calculation of validity and reliability tests that have been processed and analyzed to test the feasibility of basic motion skills test instruments in basketball.

\section{A. Results}

\section{1) Construct Validity}

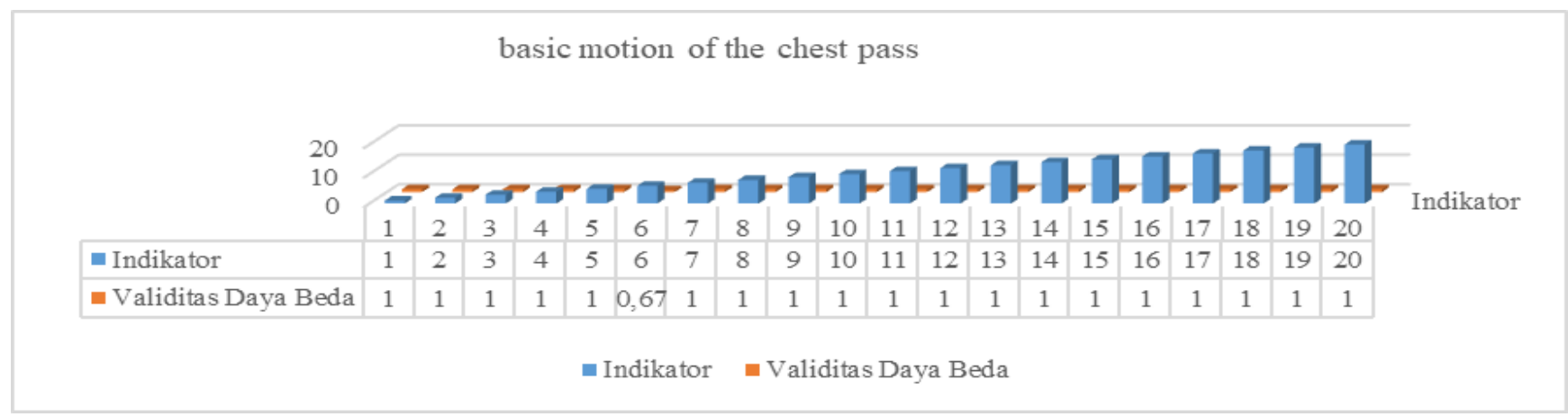

Fig. 1. Results of calculation of differential power validity for chest pass basic skill test items.

Figure 1, shows the results of calculating the validity of the different power for the chest pass basic learning outcomes test with the number of motion indicators as many as 20 items, but from a total of 20 indicators there are 1 indicator that is in the achievement of 0.67 and 19 indicators are in the achievement of the figure of 1,00 . When referring to the different power criteria, that a number above 0.40 indicates a good level of validity for different items.

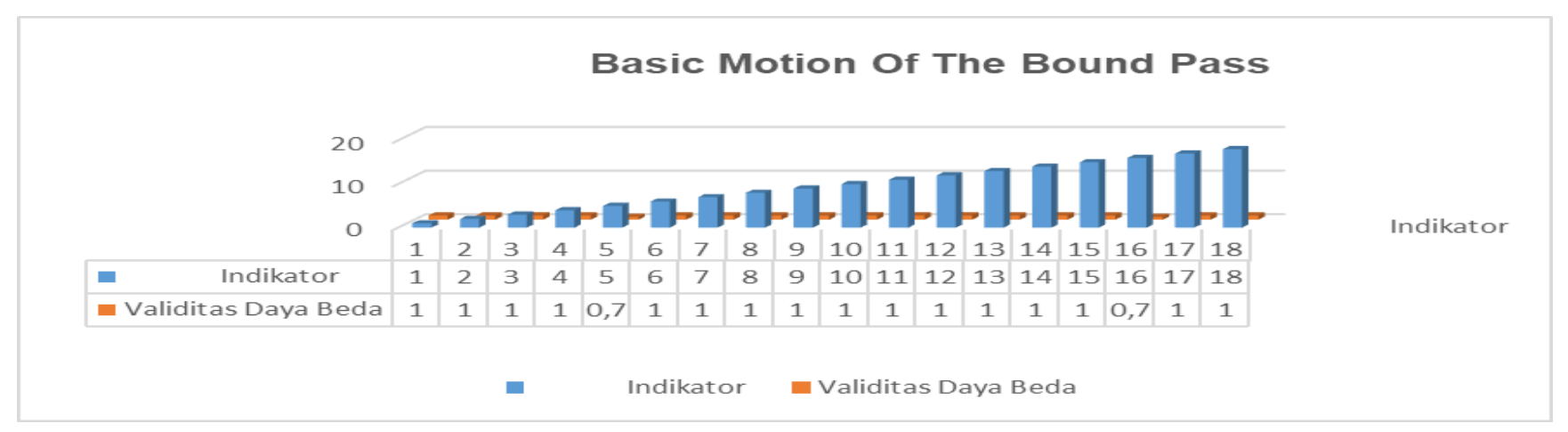

Fig. 2. Results of calculation of differential power validity for bound pass basic motion skill test items.

Figure 2, shows the results of calculating the validity of different power for bound pass basic learning outcomes test with a total of 18 motion indicators, but out of a total of 18 indicators there are 2 indicators that are on the achievement of
0.67 and 16 indicators on the achievement of 1.00 . When referring to the different power criteria, that numbers above 0 , 40 numbers indicate the level of validity of the different power items is a good item. 


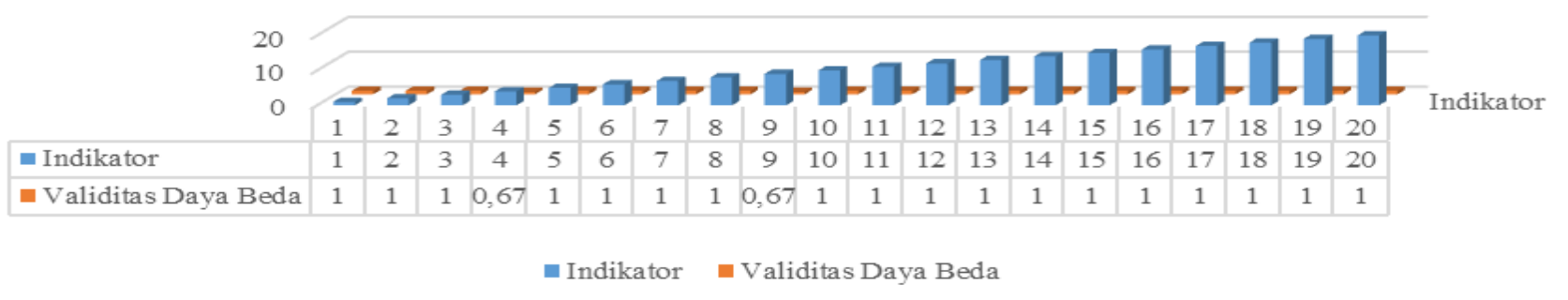

Fig. 3. Results of calculation of differential power validity for over head pass basic skill motion test items.

Figure 3, above shows the results of the calculation of the validity of the different power for the test results of basic motion learning over head pass with the number of motion indicators as many as 20 , but of the total of 20 indicators there are 2 indicators that are in the achievement of numbers of 0.67 and 18 indicators are at achievement number of 1.00 . When referring to the different power criteria, that numbers above 0 , 40 numbers indicate the level of validity of the different power items is a good item.

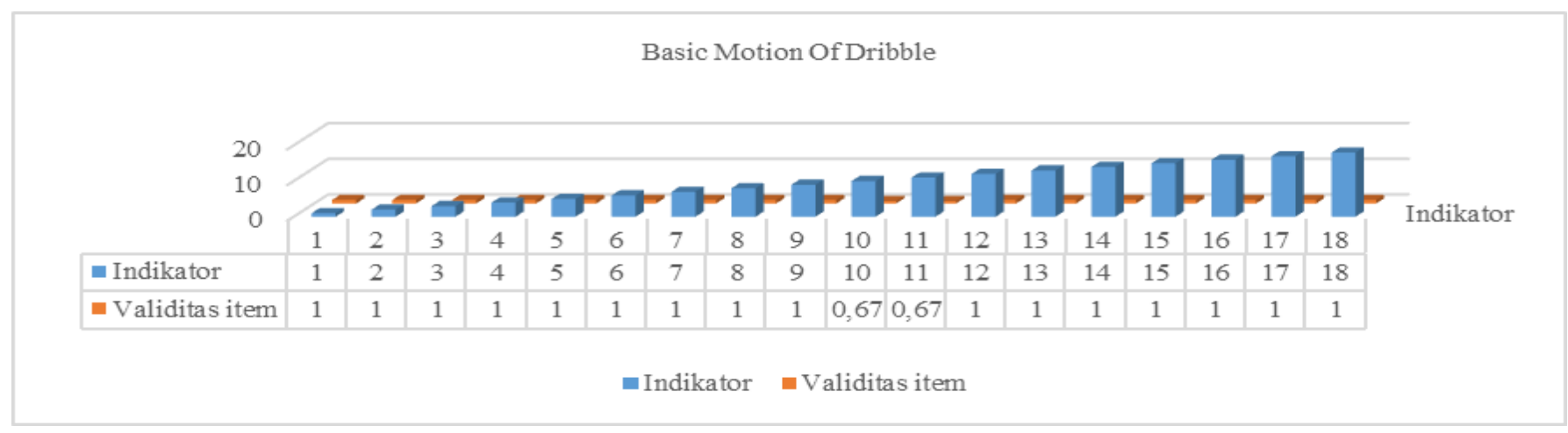

Fig. 4. Results of calculation of differential power validity for dribbling basic motion skill test items.

Figure 4 illustrates the results of calculating the validity of the different power for the basic dribbling learning outcomes test with a total of 18 indicators, but out of a total of 18 indicators there are 2 indicators that are in the achievement of 0.67 and 16 indicators are in the achievement of 1,00 When referring to the different power criteria, that the numbers above 0,40 numbers indicate the level of validity of the power of different items is a good item.

\section{B. Reliability}

The reliability test is carried out by taking the interreliability test and the reliability test. To calculate interappraiser's reliability (inter-reliability) is done by Kuder Ricardson (KR) analysis, after that the inter-reliability test (Objectivity) is performed. Following are the results of the calculation of objectivity for the instrument of mastering the motion skills of the big ball game.
TABLE I. RESULTS OF CALCULATION OF RELIABILITY WITH ANALYSIS OF KUDER RICARDSON (KR)

\begin{tabular}{|l|l|l|l|}
\hline No & Basic Motion & \multicolumn{1}{|c|}{$\begin{array}{c}\text { Reliability with } \\
\text { analisis Kuder } \\
\text { Ricardson (KR) }\end{array}$} & $\begin{array}{c}\text { Score } \\
\text { Criteria }\end{array}$ \\
\hline 1. & Chest Pass & 0,90 & Very High \\
\hline 2. & Bound Pass & 0,98 & Very High \\
\hline 3. & Over Head Pass & 0,75 & High \\
\hline 4. & Dribbling & 0,98 & Very High \\
\hline
\end{tabular}

Table 1, above shows the results of the calculation of the reliability test of the results of learning the basic motion skills of basketball games. Based on the reliability analysis using Kuder Ricardson (KR) the reliability number shows the number 0.90 for the test results of learning the basic skills of chest pass, 0.98 for the test results of learning the basic motion skills of the Bound Pass, the number 0.75 for the test results of the learning skills of motion basic over head pass, and the number 0.98 for the test results of learning basic motion skills dribbling. Referring to the results of the reliability test calculation, the basic motion skills test instrument in the 
basketball game shows a very high level of reliability for three basic movements and high for one basic motion.

TABLE II. RESUlTS OF CALCULATION OF RELIABILITY WITH THE OBJECTIVITY TEST

\begin{tabular}{|l|l|l|l|}
\hline No & \multicolumn{1}{|c|}{ Basic Motion } & $\begin{array}{c}\text { Reliability with } \\
\text { Objektifitas } \\
\text { Analysis }\end{array}$ & $\begin{array}{c}\text { Score } \\
\text { Criteria }\end{array}$ \\
\hline 1. & Chest Pass & 0,95 & Very High \\
\hline 2. & Bound Pass & 0,89 & Very High \\
\hline 3. & Over Head Pass & 0,95 & Very High \\
\hline 4. & Dreabling & 0,89 & Very High \\
\hline
\end{tabular}

In addition to carrying out the reliability test stage with the Kuder Ricardson (KR) analysis, the analysis carried out for the next reliability test is by objectivity testing. Based on the results of the calculation of reliability with objectivity test showed that the test instrument for learning the basic skills of chest pass motion was 0.95 , the test instrument for learning results for basic motion skills bound pass was 0.89 , the test instrument for learning results of basic motion skills over head pass was 0,95 , and the test instrument for learning outcomes of basic dribbling skills is 0.95 . So it can be concluded that the test instrument for learning the results of basic motion skills in basketball shows a very high level of reliability.

\section{DISCUSSION}

In this study, we developed an instrument to understand the need for measuring tools or evaluations of basic motion mastery in basketball games intended for junior high school students. We tested the construct validity and reliability with the Ricardson Kuder analysis. In the process of developing an instrument, evaluating validity and reliability is an important step [8]. The validity testing process is basically to prove whether the instrument developed is in accordance with the objectives of the process of developing an instrument and whether the indicators on this instrument can measure what should be measured [8]. The construct validity in developing this instrument is intended to provide knowledge about the ability to carry out an assessment process [9]. Construct validity basically aims to investigate whether students who have high mobility skills score better compared to students who have low ability [10]. This instrument produced 76 basic motion test items aimed at understanding the needs of evaluation in learning basketball games built on the 4 domain model contained in basketball games, as follows: chest pass, bound pass, over head pass and dribbling. This domain was extracted from the assessment of three experts and to improve the development of test instruments, we conducted a different power test analysis and from the results of the different tests there were 7 test items that were in sufficient criteria $(=0.67)$ while 69 test items were in very high criteria $(=1.00)$. Based on these results, we considered 76 items based on qualitative assessments to assess the basic motion mastery test instrument as a valid test instrument and the reduction in test items was not carried out. The development of measuring instruments or instruments needs to be tested for validity to determine the accuracy of the predictions discussed and corroborated by the scores of the predicted variables [11].

Before being used as a test tool in a study, a test instrument needs to be carried out a reliability testing process to be assessed in terms of its ability to measure changes over time [12]. Regarding the results of reliability testing, it was observed that 76 test items from four domains were in the high category. Specifically, the domain over head pass is in the high category $(=0.75)$, however these results significantly influence the use of the domain over head pass in measuring the basic motion of basketball skills. The results obtained from the study show that the scale is reliable and has a consistent structure [13]. This procedure is carried out so that the instruments that are made to the maximum have a unique use [14]. Analysis of objectivity or inter reliability, as for the results of objectivity testing on the basic motion instruments of basketball are at very high criteria $(=0.95)$. This means that this instrument has stability in measuring basic mastery of basketball. Stability in an instrument indicates the rate at which a process does not change over time [15]. The test instrument which consists of 76 test items has set standards in accordance with the basic motion tests in basketball, so this instrument can by default be used in junior high school. This is because the accuracy of the test instrument is the strongest procedure of the instrument which has the content of a descriptive statement that needs to be standardized to be clearly established from numerical data [16]. Narrative content that excels in test instruments makes it possible for teachers to set useful standards. Teachers or trainers usually use a superior perspective on content to provide an evaluation of the learning provided [17]. For example, when narrative content in test instruments is analyzed for certain characteristics that will not be felt by untrained people [18], the researcher needs to define these characteristics operationally, then test the test instrument to see whether the instrument can be understood by users [19].

\section{CONCLUSIONS}

The conclusion of this research is the basic motion skills test instrument in the basketball game with validity and reliability has a good or good level of validity and a very high level of reliability. The recommendations that can be given to physical education teachers especially physical education, sports and health teachers at the junior high school level are to be able to utilize the basic motion skills test instrument of basketball as one of the instruments to assess basic motion skills in basketball starting from the chest pass, over head pass, bound pass and dribbling for junior high school students.

\section{REFERENCES}

[1] Khaerudin, "Kualitas Instrumen Tes Hasil Belajar," Jurnal Madaniyah, vol 2(IX), pp. 212-235, 2015.

[2] A.Z. Mutaqin and L.H Lubay, "Implementasi Pembelajaran Basketball Like Games Untuk Mengembangkan Pola Gerak Dasar Lempar Dan Tangkap Pada Pembelajaran Permainan Bola Basket," Jurnal Pendidikan Jasmani Dan Olahraga, vol. 2(2), pp. 87, 2018, retrieved from: https://doi.org/10.17509/jpjo.v2i2.8185.

[3] C.T Kereh, Liliasari, P.C. Tjiang, and J. Subandar, "Validitas dan Reliabilitas Instrumen tes Matematika Dasar yang Berkaitan dengan Pendahuluan Fisika Inti,” Jurnal Inovasi Dan Pembelajaran Fisika, vol. 2(1), pp. 36-46, 2015. 
Issues of Performance-Portfolio Assessment," pp. 37-41, November 2014, retrieved from: https://doi.org/10.1080/01626620.1997.10463359.

[12] P.O. Svanberg, J. Barlow, and W. Tigbe, "Journal of Reproductive and Infant The Parent - Infant Interaction Observation Scale : reliability and validity of a screening tool," pp. 37-41, October 2013, retrieved from: https://doi.org/10.1080/02646838.2012.751586.

[13] H. Uzunboylu and C. Oz, Graphics Development for the Self-efficacy Scale: A Study of Validity and Reliability Graphics Development for the Self-efficacy Scale," pp. 1122, 2017, retrieved from: https://doi.org/10.1080/09751122.2016.11890536.

[14] G.Q. Rich, W.J. Vincent, G.Q. Rich, W.J. Vincent, A. Inexpensive, S. Caliper, W.J. Vincent, “An Inexpensive Skinfold Caliper: Validity and Reliability Assessment An Inexpensive Skinfold Caliper Validity and Reliability Assessment," June 2016, retrieved from: https://doi.org/10.1080/07303084.1983.10630508.

[15] P. Taylor, "During Activities of Various Intensities Measurements Recorded by the Equivital Lifemonitor," (January 2015), pp. 37-41, 2015, retrieved from: https://doi.org/10.1080/15459624.2012.747404.

[16] D. Kidd, G. Stewart, J. Baldry, J. Johnson, D. Rossiter, A. Petruckevitch, and A.J. Thompson, "The Functional Independence Measure: a comparative validity and reliability study," vol. 17(1), pp. 10-14, 1995.

[17] D. Kember and D.Y.P. Leung, “Assessment \& Evaluation in Higher Education Establishing the validity and reliability of course evaluation questionnaires," pp. 37-41, August 2014, retrieved from: https://doi.org/10.1080/02602930701563070.

[18] S.D. Herrmann, K.J. Heumann, C.A. Der, and B.E. Ainsworth, "Measurement in Physical Education and Exercise Science Validity and Reliability of the Global Physical Activity Questionnaire ( GPAQ )," pp. 37-41, August 2013, retrieved from: https://doi.org/10.1080/1091367X.2013.805139.

[19] J. Fethney, Y. Jeon, I. Ludford, K. Stewart, J.Fethney, Y. Jeon, K.S. Validity, "value questionnaire," 6178(November), 2015, retrieved from: https://doi.org/10.5172/conu.2013.43.2.183. 